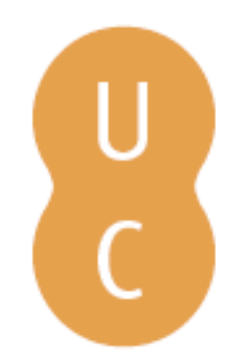

\title{
pompalina
}

\section{Augmented reality and the future of maintenance}

Autor(es): $\quad$ Oliveira, Rúben; Farinha, Torres; Raposo, Hugo; Pires, Noberto
Publicado por: Tecnologia da Universidade de Coimbra, Departamento de Engenharia Mecânica

\author{
URL \\ persistente: \\ URI:http://hdl.handle.net/10316.2/33320 \\ DOI: \\ DOI:http://dx.doi.org/10.14195/978-972-8954-42-0_12
}

Accessed : $\quad$ 26-Apr-2023 14:35:44

A navegação consulta e descarregamento dos títulos inseridos nas Bibliotecas Digitais UC Digitalis, UC Pombalina e UC Impactum, pressupõem a aceitação plena e sem reservas dos Termos e Condições de Uso destas Bibliotecas Digitais, disponíveis em https://digitalis.uc.pt/pt-pt/termos.

Conforme exposto nos referidos Termos e Condições de Uso, o descarregamento de títulos de acesso restrito requer uma licença válida de autorização devendo o utilizador aceder ao(s) documento(s) a partir de um endereço de IP da instituição detentora da supramencionada licença.

Ao utilizador é apenas permitido o descarregamento para uso pessoal, pelo que o emprego do(s) título(s) descarregado(s) para outro fim, designadamente comercial, carece de autorização do respetivo autor ou editor da obra.

Na medida em que todas as obras da UC Digitalis se encontram protegidas pelo Código do Direito de Autor e Direitos Conexos e demais legislação aplicável, toda a cópia, parcial ou total, deste documento, nos casos em que é legalmente admitida, deverá conter ou fazer-se acompanhar por este aviso.

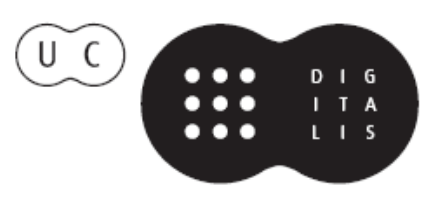




\title{
Augmented Reality and the Future of Maintenance
}

\author{
Rúben Oliveira ${ }^{1}$; Torres Farinha ${ }^{2}$; Hugo Raposo ${ }^{3}$; Noberto Pires ${ }^{4}$ \\ ${ }^{1}$ ruben.oliveira@dem.uc.pt; ${ }^{2}$ torres.farinha@dem.uc.pt; ${ }^{3}$ hugrap@gmail.com; ${ }^{4}$ norberto@uc.pt \\ 1,2,3,4 Centre for Mechanical Engineering of the University of Coimbra - CEMUC \\ Coimbra, Portugal
}

\begin{abstract}
This paper addresses the use of Augmented Reality (AR) systems to improve maintenance technicians' performance from training stage to daily interventions. The concept of AR born in industry and since then has being developed by scientists to fulfill the real demands of operational teams. It will be presented the most relevant industrial AR projects and their results, as well as others that significantly contributed for the development of $A R$ and their implementation on industrial environments, namely the progress from marker-based systems to model-based systems. Nowadays, industrial AR systems are not a faraway utopia.
\end{abstract}

To expand the benefits of AR systems for the maintenance sector, it must be combined with other tools, such as real-time monitoring, fault-diagnosis and prevention systems in order to enhance the capabilities of technicians and thus improve maintenance interventions performance.

A technician centered AR system to support maintenance interventions should recognize partially the real environment in order to represent the appropriate virtual data. The most natural procedure is to use different technologies and methodologies based on environment specifications. For this reason a modular system is proposed instead a non-customizable.

The use of markers represents a huge restriction in industrial environments for $A R$, the target objects must be found based on their natural characteristics, like textures or edges. For daily use the AR system's hardware must be portable; one of the AR challenges is to process all the data in tablets or smartphones because these devices have all the required components and, at the same time, are small enough to be carried naturally by technicians and user-friendly interfaces - however are less powerful than dedicated machines.

A timeline with most relevant projects of $A R$ applied to maintenance and assembly sector is presented, being these projects developed in industrial facilities and real work environment to make that the achieved results are close to reality.

Keywords-Industrial Augmented Reality; Maintenance trends; e-Maintenance.

\section{INTRODUCTION}

Whilst physical assets are becoming more and more complex, and consequently their maintenance more demanding, what represents an increasing complexity of maintenance operations, new methods are being developed to support technicians on their duties and to ensure a high level of overall maintenance effectiveness. These methods involve not only on condition maintenance analysis, layouts and or sequence of operations but also technological solutions to give support from the technicians on the field up to the maintenance manager. Augmented Reality (AR) is a trendy and powerful technology that may be used to improve the operability of technicians on the field.

AR is a technology that born on industrial environment [1] aiming to provide digital intuitive instructions at the same time as technicians were working on their tasks minimizing the time spent on looking for instructions manuals. In fact these objectives remain the main purpose of $\mathrm{AR}$ for industrial maintenance today. There is not a unique solution to all environments - each scenario must be carefully analyzed to choose the most suitable equipment to be used and each Working Order (WO) must be virtually prepared.

A well-documented maintenance WO is critical for a good maintenance performance, because it contains procedures and resources to complete the required tasks, and also the warnings about critical steps to avoid errors and dangerous situations. Commonly, the WO have drawings for technicians easily prepare and complete the tasks without errors but, often changes are applied on physical assets during their lifecycle, being original drawings far representations from the real scene. To overcome this problem WO must be available virtually, and ought be completed with 3D models and kept updated, [2]. Two industrial projects carried on military aeronautic industry, [3-4], attests that using updated 3D models the WO are easily created and maintained with a huge time savings.

AR is a technology that enrich real environment by superimposing virtual data on it, Fig. 1. There are a lot of variations of AR systems, starting by hardware: the virtual contents displayed, which may be 2D data or 3D models; the human-machine interaction (HMI); or even the way in which target locations are identified on a scene.

AR applied to industrial environments may looks like a utopia, but results from several projects, from different activity sectors like aerospace, automotive, defence and health show that $\mathrm{AR}$ achieves promising results and is a powerful technology to support technicians. Nevertheless, further developments on this subject will enhance its benefits.

About the equipment, while the first prototypes were limited in a major part by bulky and heavy systems a natural evolution occurs being available nowadays lightweight and portable devices. Developments keep going on hardware aiming to achieve fully wearable equipment suitable for AR systems. 


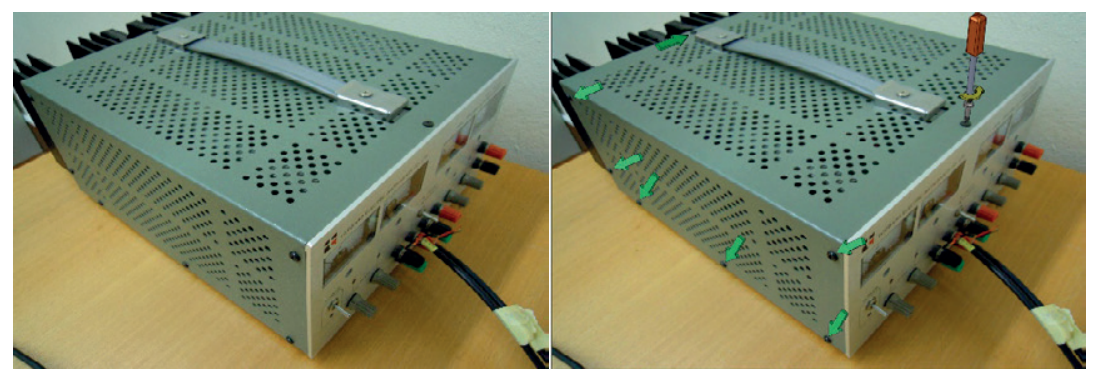

Fig. 1. (left) real environment; (right) AR environment in which instructions are superimposed and aligned with real environment

Similarly to the reutilization of $3 \mathrm{D}$ models to enhance the potential of AR on industrial maintenance sector, the AR system should be also connected to the Computer Maintenance Management System (CMMS), but at this point a huge restriction is the proprietary CMMS. Commonly, each manufacturer has their own CMMS being the communication with CMMS encrypted. However, it becomes to be common that CMMS make available the main fields of the main tables in an interface module, through Excel or similar, to share data with other systems.

But, the same is not yet possible at the level of on-condition modules, because there isn't available standard communication protocols. It is because of this that the protocols proposed by MIMOSA [5] are relevant.

The AR system ought to be connected to the general CMMS in all modules enlarging the application range of its potential.

Apart from integration with other systems, it will be noted on the projects review that physical assets' detection and tracking on non-laboratory environments is a challenging task, that's why whenever is allowed, the identification of parts is done based on AR markers. On the other hand, markers represent a restrictive and non-practical solution. For this reason the tracking subject is one of the most active subjects in terms of applied research on AR.

There are other publications that also address to a review of AR state of the art:

- The first one was published in 1997 [6] giving a definition of AR and summarizing works up to that time.

- More recently Zhou et al. [7] present an overview of papers submitted to ISMAR conference in a period of ten years. It is a scientific research oriented publication that resumes the most common techniques that were applied and most active research topics up to that date.

- Other survey, [8], is more focused on AR systems Human-Machine Interface (HMI) namely by differentiating display technologies and related equipment, like user interfaces; it also resumes several methods to track user movement and some applications of AR on different activity sectors.

- [9] besides the review being focused on construction engineering and architecture AR applications it presents AR software regularly used;
- $[10]$ conducted a survey on industrial AR - the author identified several AR projects that are related or may be applicable on industrial environments, distinguished by activity areas and evaluating if the projects have industrial applicability and their implementations stage (prototypes or final product).

It can be concluded that most projects were not user tested and industrial AR was not fully developed at that date.

The present paper presents a review of the most significant AR projects, mainly those that are related to manufacturing and maintenance environments, but besides being focused on HMI we focus on interfaces between the AR system with the maintenance network because it is expectable larger benefits as will be demonstrate.

Apart from introduction the paper is organized in four more sections:

- The following one describe the most relevant industrially-related AR projects supported by a timeline to easily compare the solutions used on each projects with the time they were developed;

- In section III is presented the main steps of an AR system and the solutions and methods available to each one;

- The up-coming solutions are presented in section IV for the reader get to know which alternatives are more probable to be available in a future;

- The final section is about conclusions of the paper.

\section{AR PROJECTS}

$\mathrm{AR}$ involves distinguished scientific topics like computer vision, HMI, 3D modelling, rendering, among others. The most active AR subjects in the terms of research were tracking, interaction and calibration, [7]. Nowadays, interaction remains to be one of the most active subjects motivated by introduction of tablets and smartphones as a single AR system user device. Additionally recognition and tracking subjects are also on top due the progress on 3D vision, namely depth sensors, and because it stills be a challenging task to identify the targets on real environments without engineering the scene.

Besides the first AR projects didn't came out of the lab, the results reached by them pointed to promising results and marked $\mathrm{AR}$ as a beneficial technology even for industrial 


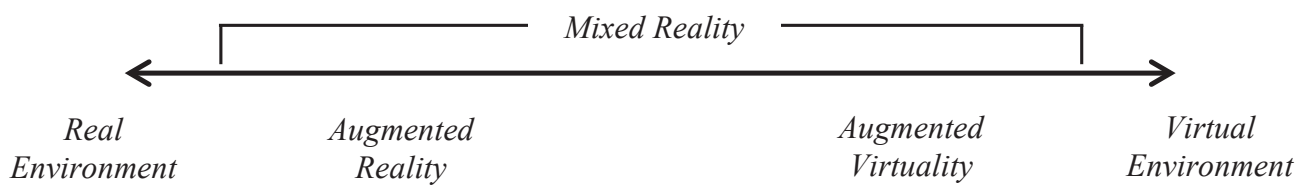

Fig. 2. Milgram's Virtuality Continuum [12]

environments if some technological constraints were suppressed. Those projects were and still being relevant to identify gaps and prospective directions for AR developments.

The KARMA project [11] was the first project conducted for maintenance applications using a see-through head mounted display to display instructions about how to perform a task on a printer. Markers were place on key components to determine in which pose instructions must be visually displayed.

In 1994 Milgram and Kishino [12] presented the "virtuality continuum" in which AR is part of Mixed Reality (MR) and is positioned on a diagram in comparison to real environment and virtual environments as exemplified on Fig. 2. Few years later Azuma [6] completed the definition of AR referring that a system to be considered as AR should:

- Combine real and virtual scenarios;

- Be interactive in real-time;

- $\quad$ And registered in 3D.

In automotive industry, a paper about a car door lock assembly using CAD data is presented in [13]; it reports to a specific task that require some preparation because the space to maneuver the door lock was very limited and hidden from the user. Additionally particular procedures must be done to complete the assembly process. To track the target part magnetic trackers were not used because their incompatibility with metal parts, that is the case of real car door. Because of that a visual tracking system with local markers were used to determine the pose of the door. Since a see-through Head Mounted Display (HMD) was used to display the augmented scenario the same markers used to track the car door were used to calibrate the HMD. The prototype was showed at an industrial fair and had attracted industrial partners to start planning a project to exploit industrial AR.

Klinker et al proposed a step-by-step maintenance interactive guide for nuclear power plant technicians to replace paper-based instructions, [14]. The same authors also referred other AR projects of industrial application, like a system to assist a skilled mechanic in disassembly procedures [15] and another two to support assembly task, [16, 17].

The year of 1999 is considered by the authors as a big start of AR developments. At that year it was published the first work [18] about what becomes to be the most popular open-source library for AR, the ARToolKit [19], which uses black and white markers (Fig. 3) to be easily detected on a scene and to determine the full pose of the target in order to present virtual data correctly aligned with the scene. In the same year had begun a succession of German funded projects, the ARVIKA project, [20,21] was the first one; from July 1999 to July 2003, it congregated relevant partners from automotive and aerospace industries and also technological centers aiming to develop AR solutions for industry, namely for maintenance and assembly tasks. The main topics of ARVIKA were improve:

- Systems interaction with speech recognition;

- The use of HMD as output devices;

- The development of a browser user interface framework;

- And the use of markers to identify target parts on real environments and to determine their pose in order to align virtual contents in the augmented scenario.

Besides several limitations, most of them related to technological developments and bulky hardware limited the portability of designed systems; a prototype named Intelligent Welding Gun was applied on real industrial environment; it uses reflective markers to estimate the pose of components on the scene, [22].

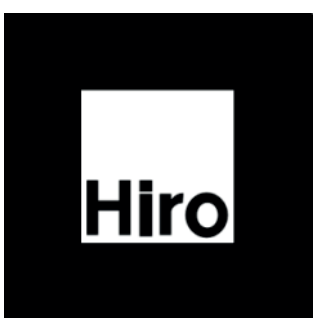

Fig. 3. Example of an ARToolkit marker

In February 2004 starts the Advanced Augmented Reality Technologies for Industrial Service Applications (ARTESAS) project with the main purpose of solving problems identified on ARVIKA, [23]. The AVILUS [24] and the AVILUSplus [25] were other two German funded projects descendant from ARTESAS that was developed almost in parallel. The main difference between those two projects was while the AVILUS was focused on industrial solutions the AVILUSplus was about researching and developing technologies that may be applied in industry some years later.

Meanwhile, other consortiums across Europe developed the industrial maintenance AR projects STARMATE and ULTRA; this project [26] was focused on development of an AR markerless maintenance guide system suitable to run on pocket 


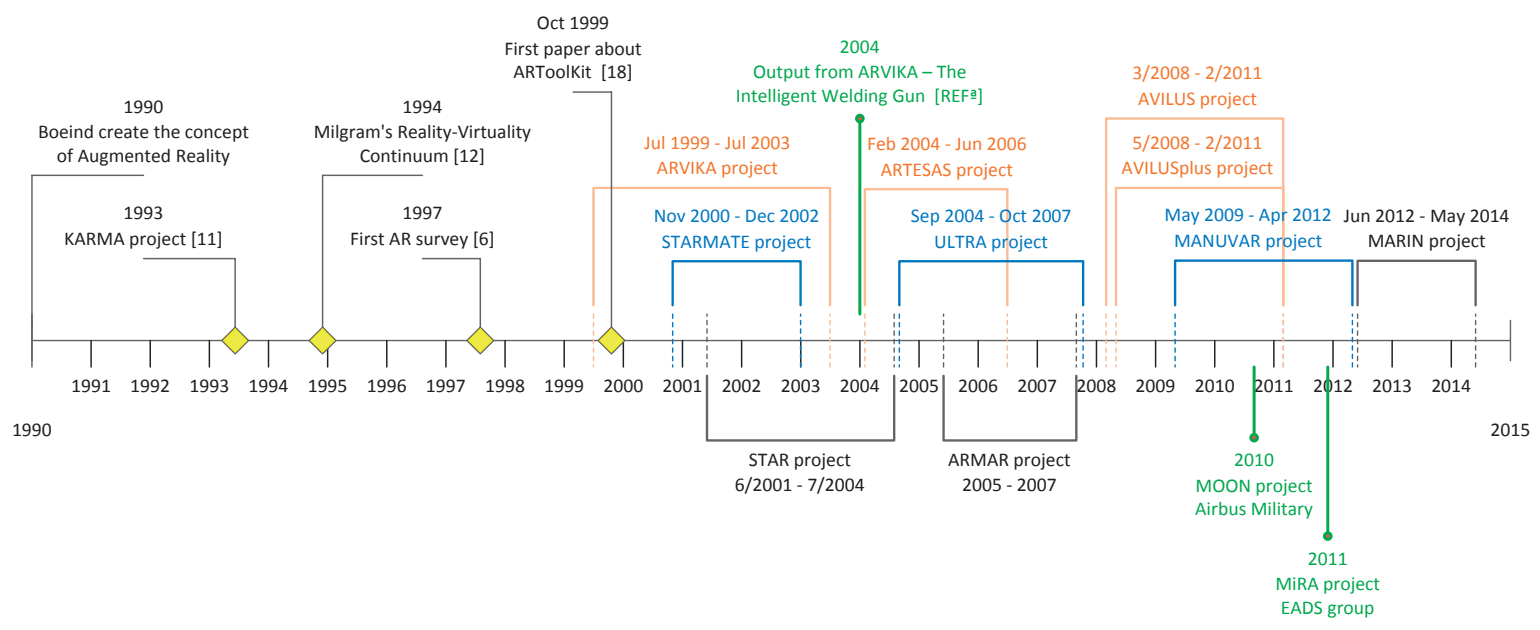

Fig. 4. Timeline of industrial AR projects

devices; in this case on a PDA. The STARMATE [27] achieved good results but was only validated on laboratorial environment. The system was prepared to rain complex maintenance tasks using two cameras and retro-reflective markers to track the targets. Despite the limitations ofSTARMATE system results were positive and AR was identified as a technology with a future potential for maintenance.

A transatlantic project name STAR (Service and Training through Augmented Reality) occurred from July 2001 to June 2004 congregated partners from Europe and USA to develop a system for online remote training and planning, according to [28]. The project aimed to evaluate the potential of the system for commercialization, [29].

To support maintenance interventions or assembly tasks on military/defence equipment two projects are known that explored such sectors. The ARMAR project [30] was about a maintenance system to assist technicians on repair sequences inside of and armored vehicle turret; it is a tracking system with ten cameras applied to track the user's head in order to indicate the location of target components using different AR output methods to evaluate the time spent on each method, [31]. Because the use of devices like a keyboard is limitative to the human interaction with AR system, ARMAR was managed through gestures recognition using a separate camera. In this project it was also evaluated the functionality of a specific Graphical User Interface (GUI) and the performance of gesture recognition algorithm for a vertical layout of virtual buttons

The second military project, named MOON [32], was conducted by AIRBUS Military in 2010 using data provided from the industrial Digital Mock-Up (iDMU) [3]. The system was designed to assist assembly operations by giving detailed instructions about procedures and rules. The results attested the capacity of AR to replace conventional paper based documentation and the benefit of a wireless system being possible to access information in the local where tasks must be done. At the same time it was verified the savings of reusing 3D information generated on previous stages; this point was already expected by other authors in [33].
The MiRA project was also conducted in EADS (European Aeronautic Defence and Space Company) group, but at this time the target were the civil airplanes A350 XWB and A380 in production lines. Even using markers MiRA was used to verify secondary structural brackets and pipes on airplanes fuselage. This system was extremely benefic allowing a minimization from 300 hours to 60 hours spent on checking those attributes and a reduction by $40 \%$ late discoveries of noncompliance; such results were published in [34].

The project ManuVAR begun in May 2009 - Manual Work Support throughout System Lifecycle by Exploiting Virtual and Augmented Reality focused on maintenance of railway sector. A consortium of 18 partners from eight European countries identified expert manual work as an expensive component of maintenance services, namely when an unpredicted failure state of a physical asset is identified and the most appropriate expert technician is not available on-site [35]; in this case it is necessary to wait until an expert reach the physical asset or contract extraordinary maintenance services nearby; both solutions increase the costs. The scope of ManuVAR was to develop an AR system to enhance the communication between remote experts and on-site workers [36]. Markers were also used on this project to identify target components once this solution is identified as a limitation being a markerless tracking system pointed as critical for introduction of AR in industrial scenarios.

Addressed to the shipbuilding industry, the MARIN (Mobile Augmented Reality Tool for Marine Industry) project purpose is to replace blueprint papers, which are often hard to handle and must be protected from rain and dust, by a mobile AR system that can store and display all the required information. The target applications for MARIN had as objective to show which equipment and where it should be installed and how to support surveys, providing intuitive information to easily check if installations are as planned, [37]. Tracking objects on such environment is a demanding task because interferences from illumination and dust are frequent. Another constraint comes when only steel walls are captured by the camera, because the lack of texture keypoints extraction and matching methodologies cannot be applied. 
Apart from these projects and referenced papers there are two other relevant marks for recent and future developments in AR that are the Kinect sale on November 2010 and the official SDK released on June 2011. Until these dates 3D Vision from depth sensors wasn't common because the high cost of required equipment. Kinect caused an extra enforce on developments based on point cloud, the use of depth data, and implicitly in 3D vision in general, being such technological solutions more affordable.

Significant developments are being made to approach AR and industrial environments; a proof is that in 2006, D. Willers from Airbus, presented several reasons about why AR failed in aircraft building industry [38] and few years later, in 2010 and 2011, two AR projects from EADS group were classified as a success, MOON and MiRA projects respectively.

Most relevant projects about maintenance and assembly operations are considered in this paper due the similarity of basic tasks of AR system, which are identifying target objects on the scene, tracking and determining their pose and present virtual instructions showing how to perform a task. On figure 6 it is presented a timeline with the same information of figure 4 but completed with papers considered relevant marks for the topic. There are additional papers addressing AR for industrial applications such as:

- $\quad$ Factory planning [39];

- An AR system for static scenes [40], with a huge potential for showrooms allowing a user to customize a product, being possible not only to change the color of the object but also to reproduce the light's shine on the augmented scenario in real time; or a training platform mainly for less skilled operators [41];

- $\quad$ Tang et al present a study comparing the effectiveness of performing the same with and without the support of an AR system, [42].

\section{AR's EQUIPMENT}

A critical specification of AR systems is the hardware, because it may happen that solutions stills being bulky, heavier and or have a few processing power for certain requirements, like faced on ARVIKA project [20]

Until a few time ago, a significant percentage of research were allocated to development of HMD [7], [9]. Nowadays, smartphones and tablets are leading the output device used because it is a mobile solution all-in-one; this kind of devices usually has integrated the following resources:

- Wireless connections;

- A camera;

- A touchscreen, that is simultaneously an input component and the output of visual data;

- A microphone and speaker;

- A reasonable processing power;

- Are lightweight and portable.
HMD may become again the most attractive output solution when wearable computing becomes competitive against tablets or smartphones.

The AR equipment will depend on environment and target object's characteristics; Fig. 5 represents the general process of an AR system with input and output hardware typically used. The calibration is mandatory step, followed by scene acquisition to get input data. Here the presence of texture, natural characteristics of target objects and illumination conditions will have a strong impact on decision about which hardware must be used. IMU and magnetic or electromagnetic sensors are a complement of the precedent ones to provide measurements with improved accuracy or to be combined with a single camera to reconstruct the scene. The reconstruction into a point cloud is an optional step that is mandatory if the use of depth data is chosen; a multi-camera approach also is applied for stereo vision purpose.

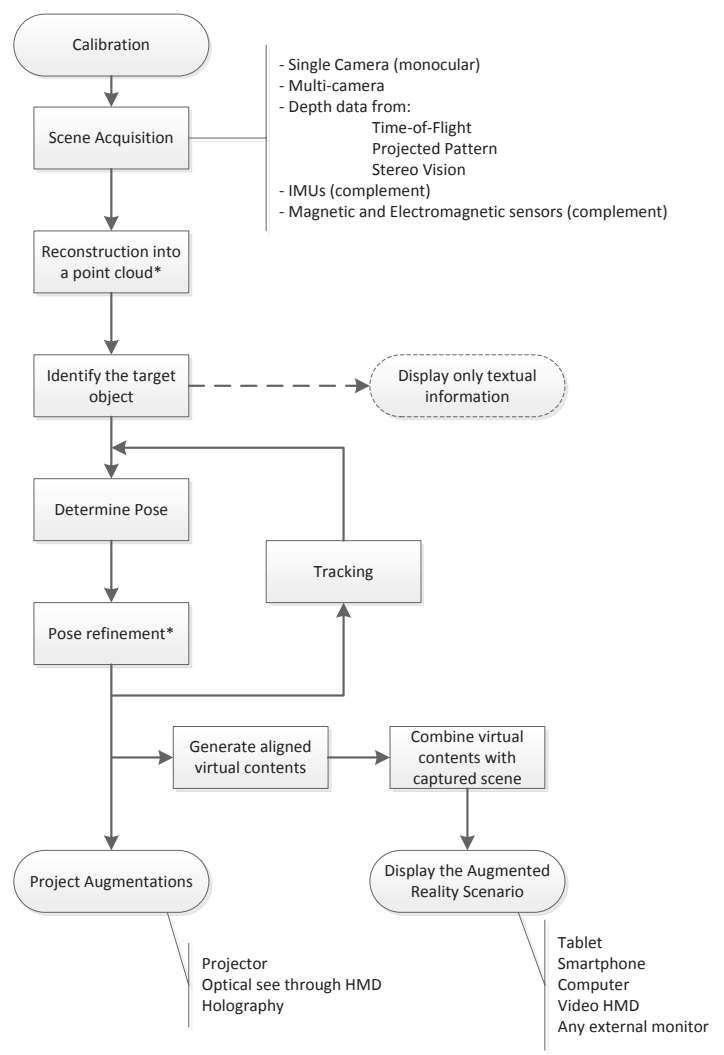

Fig. 5. AR General process

If the goal is just to present textual information, what is rare, a simple identification of the target object in the scene is sufficient; However, the full benefits from an AR system comes from displaying $3 \mathrm{D}$ animations indicating how to perform a task. In those cases it is necessary to determine the pose of the target, which is often refined by iterative methods, followed by tracking methods on sequenced images. The most delicate issue about tracking methods is the initialization, in which input measurements should be as close as possible to the real state. 


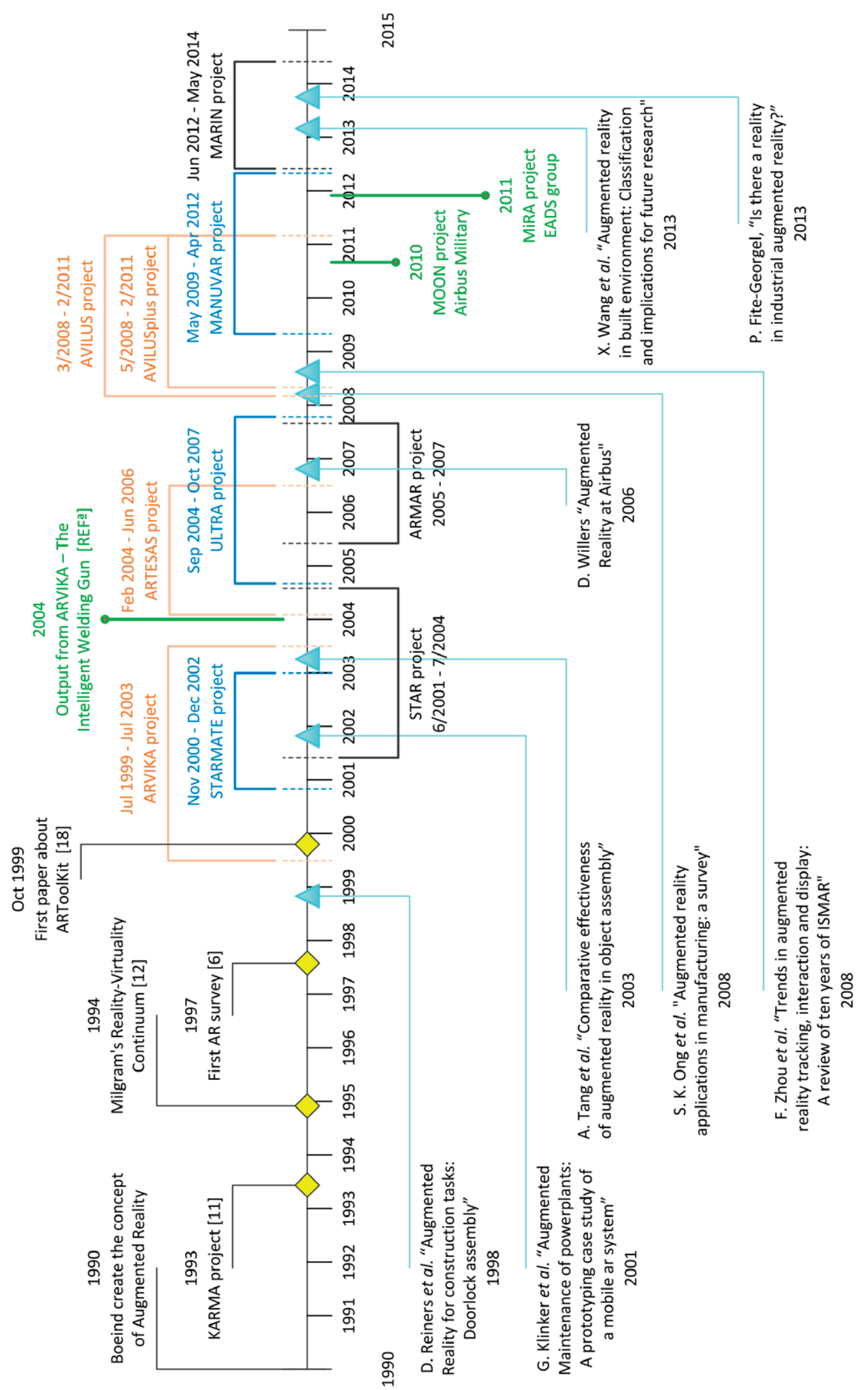

Fig. 6. Timeline of industrial AR projects with relevant papers published 
The final process of showing the virtual data superimposed in real scene is here divided in two groups:

- The first one named "Project Augmentations" where are represented technologies that only project the virtual information and don't need project the real environment. In such cases a calibration of output device is obligatory. Holography isn't yet available for this kind of applications but the authors consider that it will be accessible on future and thus holography is already classified.

- The other group present an image of the real scene combined with virtual data on a screen.

Doing a quick brief, the most suitable equipment for specific AR applications is chosen based on the following items:

- Budget;

- Scene characteristics;

- System's portability;

- On measurement's precision and reliability.

\section{UP-COMING SOLUTIONS}

It is difficult to describe very accurately what will the next AR solution or which equipment will be the most reliable for AR purposes; but, in general, it was identified an actual trend to 3D vision, namely the use of depth sensors and thus further improvements on point cloud works. A very interesting work on $3 \mathrm{D}$ reconstruction of scenes is presented by Whelan et al in [43]. GPU processing also represents one trend method with vast benefits for computer vision area and consequently for AR too.

About mobile devices it is a little bit harder to point which will be the next most used device; both smartphones and tablets are becoming more powerful in term of processing capacity and graphics. At the same time a new generation of laptops are already available which are the convertible laptops (all-in-one) that may be transformed on a tablet, being an alternative to these. Nevertheless, wearable computer with a HMD is an active research topic for a mid and long-term solutions.

So far, the AR systems implemented on industrial facilities are a unique solution for specific tasks and don't communicate with the remaining maintenance infrastructure. This is a very sensitive topic that, for sure, will enlarge the applicability of AR, using a mobile device not only to receive instructions about how to perform a task but also to report the conclusion of a task or even to report faults.

The identification of target parts stills be a high priority concern since the global effectiveness of the AR system depends directly on it. Currently, the authors are working on this topic in order to develop a system to detect and track robustly the targets based on their natural features, like shape and texture.

\section{CONCLUSIONS}

There are several AR solutions available and adequate for training environments but to a generic markerless solution to be applied on open environments is not yet available, mainly because the interferences on computer vision sub-system which is, nowadays, the most critical part of an AR system.

Nevertheless, for pre-defined operations, it was proved that the use of AR is benefic because, in general, the same task is done in less time, are committed less errors and the quality is improved. For small companies AR isn't affordable yet, but for the bigger ones where the same tasks are performed many times it is profitable. Additionally, for critical services, like aeronautic sector or in nuclear power plants, in which safety is a major concern and all the work is done using drawings and checklists, AR have potential to improve the results.

Industrial AR is a long journey that is only in the beginning but new methods must be tested to verify their benefits and gaps that must be solved by future solutions.

The objective of the survey presented in the paper is to have a state-of-the-art that can be used to briefly identify previous projects, their results, technologies available at the time and to find the most relevant publications on industrial AR related to the subjects of maintenance in order to find practical examples to support the evaluation of using AR, and also to easily identify gaps to be overcome with new research projects.

\section{ACKNOWLEDGMENT}

This work was supported by a grant from Fundação para a Ciência e a Tecnologia - FCT by contract SFRH/BD/86816/2012.

\section{REFERENCES}

[1] D. Sims, "New realities in aircraft design and manufacture," Computer Graphics and Applications, IEEE, vol. 14, no. 2, pp. 91-, March 1994

[2] R. Oliveira, T. Farinha, S. Singh, and D. Galar, "An augmented reality application to support maintenance - is it possible?" in Proc. Maintenance Performance Measurement and Management (MPMM) 2013 2013, pp. 260-271. [Online]. Available: https://online.unileoben.ac.at/mu_online/voe_main2.getVollText?pDocumentNr=142932\&pCurrPk=32372

[3] F. Mas, J. L. Menéndez, J. Serván, A. Gómez, and J. Ríos, "Aerospace industrial digital mock-up exploitation to generate assembly shop floor documentation," in 29th Intl. Manufacturing Conference (IMC29), Belfast, 2012.

[4] J. Serván, J. M. Rubio, F. Mas, A. Gómez, and J. Ríos, “Augmented reality using laser projection for the airbus a400m wing assembly," in 29th Intl. Manufacturing Conference (IMC29), 2012, pp. 154-162.

[5] Mimosa - an operations and maintenance information open system alliance. [Online]. Available: http://www.mimosa.org/

[6] R. T. Azuma, "A survey of augmented reality," Presence: Teleoperators and Virtual Environments, vol. 6, no. 4, pp. 355-385, Aug. 1997.

[7] F. Zhou, H.-L. Duh, and M. Billinghurst, "Trends in augmented reality tracking, interaction and display: A review of ten years of ismar," in Mixed and Augmented Reality, 2008. ISMAR 2008. 7th IEEE/ACM International Symposium on, Sept 2008, pp. 193-202.

[8] D. W. F. van Krevelen and R. Poelman, "A Survey of Augmented Reality Technologies, Applications and Limitations," The International Journal of Virtual Reality, vol. 9, no. 2, pp. 1-20, Jun. 2010.

[9] X. Wang, M. J. Kim, P. E. Love, and S.-C. Kang, "Augmented reality in built environment: Classification and implications for future research," Automation in Construction, vol. 32, no. 0, pp. $1-13,2013$. [Online]. Available: http://www.sciencedirect.com/science/article/pii/S0926580512002166

[10] P. Fite-Georgel, "Is there a reality in industrial augmented reality?" in Mixed and Augmented Reality (ISMAR), 2011 10th IEEE International Symposium on, Oct 2011, pp. 201-210. 
[11] S. Feiner, B. Macintyre, and D. Seligmann, "Knowledge-based augmented reality," Commun. ACM, vol. 36, no. 7, pp. 53-62, Jul. 1993. [Online]. Available: http://doi.acm.org/10.1145/159544.159587

[12] P. Milgram and F. Kishino, "A Taxonomy of Mixed Reality Visual Displays," IEICE Transactions on Information Systems, vol. E77-D, no. 12, pp 1321-1329, Dec. 1994.

[13] D. Reiners, D. Stricker, G. Klinker, and S. Müller, "Augmented reality for construction tasks: Doorlock assembly," in Proceedings of the International Workshop on Augmented Reality : Placing Artificial Objects in Real Scenes: Placing Artificial Objects in Real Scenes, ser. IWAR '98. Natick, MA, USA: A. K. Peters, Ltd., 1999, pp. 31-46. [Online]. Available: http://dl.acm.org/citation.cfm?id=322690.322694

[14] G. Klinker, O. Creighton, A. H. Dutoit, R. Kobylinski, C. Vilsmeier, and B. Brugge, "Augmented maintenance of powerplants: a prototyping case study of a mobile ar system," in Augmented Reality, 2001. Proceedings. IEEE and ACM International Symposium on, 2001, pp. 124-133.

[15] D. Curtis, C. Esposito, P. Gruenbaum, A. Janin, and D. Mizell, "The boeing portable maintenance aide," in Demonstration at the 1st International Symposium on Augmented Reality (ISAR'00), Munich, Oct 2000.

[16] D. Curtis, D. Mizell, P. Gruenbaum, and A. Janin, "Several devils in the details: Making an ar app work in the airplane factory," in Augmented Reality-Placing Artificial Objects in a Real Scene, R. Behringer, G. Klinker, and D. Mizell, Eds. A.K. Peters, 1999, pp. 47-60.

[17] J. Molineros, V. Raghavan, and R. Sharma, "AREAS: Augmented Reality for Evaluating Assembly Sequences," in Augmented Reality-Placing Artificial Objects in a Real Scene, R. Behringer, G. Klinker, and D. Mizell, Eds. A.K. Peters, 1999, pp. 91-99.

[18] H. Kato and M. Billinghurst, "Marker tracking and hmd calibration for a video-based augmented reality conferencing system," in Augmented Reality, 1999. (IWAR '99) Proceedings. 2nd IEEE and ACM International Workshop on, 1999, pp. 85-94.

[19] ARToolKit. [Online]. Available: http://www.hitl.washington.edu/artoolkit/

[20] J. Weidenhausen, C. Knoepfle, and D. Stricker, "Lessons learned on the way to industrial augmented reality applications, a retrospective on ARVIKA," Computers and Graphics, vol. 27, no. 6, pp. 887-889, December 2003.

[21] W. Friedrich, "Arvika - augmented reality for development, production and service," in 1st International Symposium on Mixed and Augmented Reality (ISMAR '02), I. C. Society, Ed., 2002, pp. 3-4.

[22] F. Echtler, F. Sturm, K. Kindermann, G. Klinker, J. Stilla, J. Trilk, and H. Najafi, "EnglishThe intelligent welding gun: Augmented reality for experimental vehicle construction," in EnglishVirtual and Augmented Reality Applications in Manufacturing, S. Ong and A. Nee, Eds. Springer London, 2004, pp. 333-360.

[23] Artesas - advanced augmented reality technologies for industrial service applications. [Online]. Available: http://edok01.tib.uni-hannover.de/edoks/e01 fb07/551471905.pdf

[24] Avilus - angewandte virtuelle technologien im produkt-und produktionsmittel-lebenszyklus. [Online]. Available: http://www.vdtc.de/content/dam/iff/vdtc/de/dokumente/avilus-vr-fuer-

produktmittellebenszyklus.pdf

[25] Avilusplus - angewandte virtuelle technologien mit langfristfokus auf den produkt- und produktionsmittel-lebenszyklus. [Online]. Available: http://www.avilusplus.de/

[26] P. Riess, D. Sticker, G. Voss, and W. Mueller-Witting, "ULTRA Ultra Portable Augmented Reality for Industrial Maintenance Applications," CG Topics, vol. 6, pp. 16-18, 2006. [Online]. Available: http://portal.hsweingarten.de/c/document_library/get_file?uuid=fd9b2146-ea78-4467-b96e5 eb14dc8ed08\&groupId $=26000$

[27] B. Schwald and B. de Laval, "An augmented reality system for training and assistance to maintenance in the industrial context," WSCG, vol. 11, no. 1, pp. 3-7, 2003.
[28] S. K. Ong, M. L. Yuan, and A. Y. C. Nee, "Augmented reality applications in manufacturing: a survey," International Journal of Production Research, vol. 46, no. 10, pp. 2707-2742, 2008. [Online]. Available: http://dx.doi.org/10.1080/00207540601064773

[29] A. Raczynski and P. Gussmann, "Services and training through augmented reality," in Visual Media Production, 2004. (CVMP). 1st European Conference on, March 2004, pp. 263-271.

[30] (2013) Armar project webpage. [Online]. Available: http://graphics.cs.columbia.edu/projects/armar/index.htm

[31] S. Henderson and S. Feiner, "Exploring the benefits of augmented reality documentation for maintenance and repair,"Visualization and Computer Graphics, IEEE Transactions on, vol. 17, no. 10, pp. 1355-1368, Oct 2011.

[32] J. Serván, F. Mas, J. L. Menéndez, and J. Ríos, "Using augmented reality in airbus a $400 \mathrm{~m}$ shop floor assembly work instructions," AIP Conference Proceedings, vol. 1431, no. 1, pp. 633-640, 2012. [Online]. Available: http://scitation.aip.org/content/aip/proceeding/aipcp/10.1063/1.4707618

[33] J. T. Farinha, R. Oliveira, I. Fonseca, and L. A. Ferreira, "Technical asset management beyond tomorrow," in Electronic Proceedinds of The 2nd World Maintenance Forum, Lugano, Switzerland, Sept. 2013.

[34] EADS, "EADS 2011 Coporate Responsability \& Sustainability Report,” EADS, Tech. Rep., 2011.

[35] M. Leva, A. M. Kay, T. Smith, A. Diez, J. Azpiazu, P. Liston, and S. Cromie, "The use of augmented reality to support maintenance: Human factors issues and advantages," in Irish Ergonomics Society Annual Conference 2011, L. W. O’Sullivan and C. Leva, Eds., 2011, pp. 37 - 47.

[36] J. Azpiazu, S. Siltanen, P. Multanen, A. Mäkiranta, N. Barrena, A. Díez, J. Agirre, and T. Smith, "Remote support for maintenance tasks by the use of Augmented Reality: the ManuVAR," in CARVI 2011: IX Congress on virtual reality applications, Spain, Nov 2011.

[37] J.-P. Arimaa, R. Suominen, A. Euranto, O. Lahdenoja, T. Knuutila, and T. Lehtonen, "Tracking and integration aspects of a mobile augmented reality tool for shipbuilding," in EEE ISMAR 2013 Joint Workshop on Tracking Methods \& Applications and TrakMark, Adelaide, Australia, Oct 2013.

[38] D. Willers, "Augmented reality at airbus," in International Symposium on Mixed \& Augmented Reality 2006, 2006. [Online]. Available: http://ismar2006.vgtc.org/images/3a-airbus.pdf

[39] K. Pentenrieder, C. Bade, F. Doil, and P. Meier, "Augmented reality-based factory planning - an application tailored to industrial needs," in 6th IEEE and ACM International Symposium on Mixed and Augmented Reality, ser. ISMAR '07. Washington, DC, USA: IEEE Computer Society, 2007, pp. 19. [Online]. Available: http://dx.doi.org/10.1109/ISMAR.2007.4538822

[40] G. Gay-Bellile, S. Bourgeois, M. Tamaazousti, S. Naudet-Collette, and S. Knodel, "A mobile markerless augmented reality system for the automotive field," in IEEE ISMAR 2012 Workshop on Tracking Methods and Applications, 2012.

[41] S. Webel, U. Bockholt, T. Engelke, N. Gavish, M. Olbrich, and C. Preusche, "An augmented reality training platform for assembly and maintenance skills," Robotics and Autonomous Systems, vol. 61, no. 4, pp. 398 - 403, 2013, <ce:title>Models and Technologies for Multi-modal Skill Training</ce:title>. [Online]. Available: http:/www.sciencedirect.com/science/article/pii/S0921889012001674

[42] A. Tang, C. Owen, F. Biocca, and W. Mou, "Comparative effectiveness of augmented reality in object assembly," in Proceedings of the SIGCHI Conference on Human Factors in Computing Systems, ser. CHI '03. New York, NY, USA: ACM, 2003, pp. 73-80. [Online]. Available: http://doi.acm.org/10.1145/642611.642626

[43] T. Whelan, M. Kaess, J. Leonard, and J. McDonald, "Deformationbased loop closure for large scale dense rgb-d slam," in Intelligent Robots and Systems (IROS), 2013 IEEE/RSJ International Conference on, Nov 2013, pp. $548-555$. 